\title{
Clinically relevant infections in hematatology and oncology
}

\author{
Christoph Steininger
}

Infectious diseases are closely related to many cases of cancer-either directly by causing or propagating cancer or indirectly by providing the grounds for opportunistic infections or complicating treatment of cancer. Worldwide, a large fraction of all cancer cases-2 million (16.1\%) of the total 12.7 million new cases annually-are attributable to infectious diseases. Less developed countries are affected more (22.9\%) than more developed countries $(7.4 \%)$ as hygiene as well as prevention or treatment of infectious disease are less developed in these regions. Incidence of infection-related cancer cases varies 10 -fold by region from $3.3 \%$ in Australia and New Zealand to $32.7 \%$ in sub-Saharan Africa [1]. The most relevant infectious pathogens identified for the development of cancer are Epstein-Barr virus, Helicobacter pylori, hepatitis $B$ and $C$ virus, human herpesvirus 8 , human papillomavirus and Opisthorchis viverrini. Nevertheless, the number of cancer cases related to yet unknown infectious causes or unrecognized causal links between infection and cancer is likely much higher. The current issue of the Magazine of European Medical Oncology (MEMO) highlights the diversity of infectious pathogens related to cancer cases. Five different reports describe infectious complications or opportunistic infections in patients with malignant diseases including viral and bacterial pathogens [2-6]. In an additional contribution, the clinical relevance of bacterial infections and their therapy with novel antimicrobial drugs is discussed. The field of cancer research focusing on infectious pathogens that modulate or cause cancer is highly active and the

\section{Assoc. Prof. Dr. C. Steininger $(\bowtie)$}

Division of Infectious Diseases and Tropical Medicine,

Department of Medicine I, Medical University of Vienna,

Währinger Gürtel 18-20, 1090 Vienna, Austria

christoph.steininger@meduniwien.ac.at current submissions to the journal emphasize this highly dynamic and interesting trend.

Conflict of interest C. Steininger declares that he has no competing interests.

\section{References}

1. de Martel C, Ferlay J, Franceschi S, Vignat J, Bray F, Forman D, Plummer M. Global burden of cancers attributable to infections in 2008: a review and synthetic analysis. Lancet Oncol. 2012;13(6):607-615.

2. Rumpold H. Lethal human metavirus pneumonia in a patient with chronic lymphocytic leukemia. memo. 2021;14(3). https://doi.org/10.1007/s12254-021-007340 .

3. Fritsche G. Clinically relevant infections in hematology and oncology: bacterial infections and the role of novel antibiotics in times of multidrug resistance. memo. 2021;14(3). https://doi.org/10.1007/s12254-021-00702-8.

4. Mayrhofer K, Hilbe W. Cryptococcus neoformans meningitis in a patient with diffuse large B-cell lymphoma-a case report. memo. 2021;14(3). https://doi.org/10.1007/ s12254-021-00721-5.

5. Fauser J, KöckS, Gunsilius, E, etal. Death of unknowncause? Post-mortem diagnosis of fulminant course of an EBV-associated secondary hemophagocytic lymphohistiocytosis. memo 2021;14(3). https://doi.org/10.1007/s12254-02100701-9.

6. Chaari A, TurakE, Nashaat, M, et al. Sphenoidal mucormycosis associated with large B-cell lymphoma: case report and literature review. memo 2021; 14(3). https://doi.org/ 10.1007/s12254-021-00705-5.

Publisher's Note Springer Nature remains neutral with regard to jurisdictional claims in published maps and institutional affiliations. 